\title{
How to Support Poor Vietnamese Consumers to Deal with Food Price Volatility and Food Safety Issues
}

\author{
Tran Cong Thang and Dinh Thi Bao Linh
}

\begin{abstract}
With 66 per cent of the population living in rural areas, over half depending on farm activities, food security and food safety are now two sides of the government effort to ensure food accessibility for the poor in Vietnam. While people living on low incomes may have to choose cheaper food over safer food, they are now more aware of food safety issues, and need more support to access safe food. After a long time of focusing on increasing food security in terms of quantities, new efforts are now needed to change the practice and awareness of stakeholders to move to quality-oriented production and consumption, including creating reasonable incentives for food producers, socialising of food safety monitoring and improving food safety inspection in Vietnam.
\end{abstract}

\section{Introduction}

The poverty rate in Vietnam has decreased over a long period, at an impressive rate of 2 per cent per year. Through the national targeted programme on poverty reduction, the programme on rapid and sustainable poverty reduction ${ }^{1}$ and support from non-governmental organisations (NGOs), the poverty rate has been brought down from 22 per cent in 2005 to 7.6 per cent in 2013 (GSO 2013). Per capita average income of Vietnam is up from US $\$ 1,200$ in 2009 to US $\$ 2,200-2,300$ in 2014 , and the unemployment rate remains low (GSO 2014). For low-income consumers, price used to be the most important factor affecting decisions about what food to buy, but with poverty on the decline, they now pay increasing attention to food safety. With 66 per cent of the population living in rural areas, over half depending on farm activities, eco-social problems affecting food production and safety have become more prominent. These include diseases and pestilence affecting humans, animals and crops; food safety issues including food hygiene and the misuse of chemicals in food products; and the broader effects of environmental pollution. These problems are affecting the life and health of people, especially the poor. Therefore, policies and programmes to help poor consumers to deal with unsafe food while also increasing production have become a priority for the Government of Vietnam.
This article looks at issues of food safety from the perspective of poor consumers living in three provinces in Vietnam, drawing on three rounds of qualitative research undertaken between 2012 and 2014. It provides an assessment of new Government of Vietnam policies and programmes designed to help poor Vietnamese people secure food in sufficient quantity and quality, and gives the perspective of how people have been living and adjusting their consumption patterns in light of concerns about food safety. As one of the factors that influences the aims of poverty reduction and social stability of the country, the article will document how poor consumers are experiencing and perceiving food safety issues and identify the implications for policy and practice. In the context of Vietnam, food security and food safety are two sides of the government effort to ensure food accessibility for the poor, which should be considered in terms of both quantity and quality. People living on low incomes may have to choose cheaper food over safer food, but they are now more aware of food safety issues, and need more support to access safe food.

As part of the Life in a Time of Food Price Volatility project (IDS 2014), the Institute of Policy and Strategy of Agriculture and Rural Development (IPSARD) conducted qualitative field surveys in four research sites in three provinces of Vietnam. 
The four research sites included (1) Quỳnh Mai Ward, Hai Ba Trung District, Hanoi City; (2) Phu Dien Commune, Tu Liem District, Hanoi City; (3) Nghi Văn Commune, Nghi Loc District, Nghe An Province; and (4) Luong An Tra Commune, Tri Ton District, An Giang Province. Of these, Hanoi City has the highest living standards, then An Giang and Nghe An respectively. In Hanoi, most people do not depend on agriculture, while in Nghi Văn, Nghe An, most people are farmers who produce and sell rice in the domestic market. An Giang is in the Mekong river delta of Vietnam, one of the country's rice-exporting provinces. But notably, Vietnam exports medium- or low-quality rice, mostly to developing countries with lower prices in comparison to Thai and Chinese rice, while rice for domestic consumption tends to be higher quality and more expensive. In each site, household and key informant interviews were conducted as well as focus group discussions.

The research on which the article is based involved (a) qualitative research gathered in the course of the project research, (b) key informant interviews with government officials and experts, and (c) price data analysis and policy and secondary document review on food safety problems and policy support from the government. Price data were collected from the database of IPSARD ${ }^{2}$ while materials on food supply and safety issues were collected from the Ministry of Agriculture and Rural Development (MARD) and the Ministry of Health.

\section{Problems of food safety}

The research finds that not only are different regions differently affected by food safety issues, but priorities also vary regionally. Households in the centre of the country tend to attach most importance to housing, and save money to build big and beautiful houses; nutrition and family meals are a lower priority. In this region, almost one fifth of the households we talked to were building new houses, even though most had to borrow money to finance this. In the south, respondents seemed more interested in nutrition and how the family was eating, and it is in this region that people spend the most on daily meals. In the northern urban areas in Hanoi, people were paying attention to food safety and hygiene issues out of concern for their health, even though their first priority was always their children's education.

In Vietnam, due to an increasing number of food poisoning cases in 2011 and 2012 (141 and 164 cases respectively), the government had to pay more attention on assuring food safety. The incidence of serious cases of food poisoning has since decreased to 127 in 2013 and 121 in 2014, but food safety remains a big concern of the government because the numbers of deaths are still high (20 in 2013 and 24 in 2014) (GSO 2014).

One action the Government of Vietnam has taken has been to try to apply agricultural good practices through the VietGAP (Vietnamese Good Agricultural Practices) policy. ${ }^{3}$ It is based on the principle that improving quality pushes the agricultural export up the value chain to higher standard markets. The export value of agro-forestryfishery products rose from US $\$ 19.53$ billion in 2010 to US $\$ 27.47$ billion in 2013 (GSO 2014). Despite improvements in agricultural quality for export, however, domestic food consumers are facing problems of unsafe food with potentially bad effects on human health. Although the surveyed households did not report any serious disease related to consumption of unsafe food, there was widespread worry about the safety of the foods they were consuming.

One rice-farming research participant in Luong An Tra Commune gave the following response when asked about standards:

Q. Do you produce rice in accordance with any standards? (e.g. SRI, VietGAP, Global gap, organic).

\section{A. No, I have never heard about those standards.}

While many people have not heard about food production standards, all respondents mentioned their worries about unsafe food. Particular fears were noted around vegetable and pork production because of the fear of abuse of plant protection chemicals (pesticides and insecticides) and substances fed to livestock to induce faster weight gain. To cope with this situation, many households in An Giang and Nghe An provinces have taken to producing their own fish, chicken and vegetables. Only in Hanoi City do households have no choice but to buy their own food, and if possible they prefer to shop in supermarkets and safe foods shops. These outlets convince consumers that their food is safe by displaying food safety certification issued by the competent authorities. One household member ${ }^{4}$ from Hanoi explained:

I have known about food safety by watching TV. We are often worried about the foodstuff quality, so we asked for our grandchildren not to eat out. We are even worried when eating tofu. If my wife can go to the supermarket, the foods will be safer but it is too far for her to go to the supermarket. 
All respondents declare that they are more interested now in choosing safe foods than they were in the past, reflecting sharply rising concerns about this issue. But not everyone can afford to eat food they consider safe: poorer households often have to borrow money from relatives or neighbours, and so accept cheap food even when they fear it is unsafe. Notes from a focus group discussion ${ }^{5}$ in Nghe Văn Commune documented the following:

Everyone in [this] group is very concerned about the safety of food. Sometimes people do not dare to buy foods in the market because they [are] afraid these foods contain too much chemical preservatives. At present, people still have to buy 70 per cent of their food because the land and crop diseases prevent them from producing [enough] foods themselves. There is a woman who ate cabbage bought in the market, then she had stomach ache and diarrhoea. Now people do not dare to eat vegetables from the [local] market.

People are very worried about food safety because food provenance is not easy to trace and production methods in Vietnam are poorly regulated, with an emphasis on quantity rather than quality. Vietnamese people tend to have little information about the origin of foods, especially in the rural areas where fresh foods at local markets are not packed or labelled. Mr S., ${ }^{6}$ a 76-year-old man explained: 'I only buy vegetables with poor appearance. If the vegetables are good-looking, we dare not buy. At this time, pak choi and sweet leaf bush need to use much pesticides.'

The Government of Vietnam recognises these concerns, and has issued different policies such as GAP to support the agricultural production practices, but more effective policies are needed to improve food safety and collaboration between relevant agencies in food safety monitoring and management. Many people in the three sites believe that government communications regarding alerting and disseminating information about unsafe foods to the whole community is inadequate. In the rural research sites, farmers suggested that dissemination of laws and regulations on food safety is not considered important, with little information on these matters being shared by village and commune loudspeakers. This system of rural communication is only used to make announcements about agriculture production. Notes from a focus group ${ }^{7}$ in Nghe An documented local channels of communication about food:
There are communications through local radio speakers, but very little. People usually get the information through TV. Most people do not know the state regulations on hygiene and food safety.

\section{Policies and issues}

\subsection{Food security policies and issues}

Vietnam has put primary emphasis on ensuring production quantity. It has issued many policies to protect and maintain the natural resources as well as policies on improving the infrastructure for agricultural production, with the aim of ensuring the food supply. In 2009, the government issued Resolution No. 63/NQ-CP to ensure national food security. It offers a package of measures to meet quantitative targets: ${ }^{8}$

By 2020, protecting 3.8 million hectares of rice land to yield 41-43 million tons of rice, meeting all the demand for domestic consumption, exporting about 4 million ton of rice per year; increasing corn acreage to 1.3 million hectares and the quantity of corn up to 7.5 million tons; ensuring fruit trees planted area of 1.2 million hectares to yield 12 million tons of fruits; 1.2 million ha of vegetables to yield 20 million tons of vegetable, producing 8 million tons livestock meat; 1 million tons of fresh milk, 14 billion unit of poultry eggs (translation from Resolution No. 63/NQ-CP, page 2).

This policy supports the production of rice and other crops in order to assure food security. In addition, it provides important measures to reduce production costs, and increase incomes for rice farmers, aiming to generate profits from rice production of over 30 per cent compared to the cost of production. In 2012, the government also issued policies on management and use of rice land. ${ }^{9}$ Accordingly, the policies support farmers to maintain and recover rice production in case of natural epidemic disease, and support for reclamation and improvement of rice land. Based on the rice area, the central budget supports local budgets (including investment and regular expenditure) for rice production.

These policies suffer from a number of weaknesses. They are difficult to implement and monitor because of the large number of farming households approximately 10 million households spread through the eight regions and 63 provinces of the country. It is also difficult to determine whether an upland rice area is in the planning area or not. The support is not enough to adequately supplement the income of 
rice-growing households compared to other farmer households, or households that have switched to work in non-agricultural sectors. In addition, due to very small-scale production, support per household is so small that it cannot be an incentive to farmers to maintain production and food supply.

Field research for the Life in a Time of Food Price Volatility study in 2014 found that policies supporting agricultural production in Nghe An and An Giang provinces have mostly only been implemented in instances of serious disease epidemics or disasters. Since 2011, there has also been an additional support policy for paddy producers at 500,000 VND per hectare, but this policy has not been very effective because the production scale of households tends to be smaller, and the procedure to get support is complex. Smallholder producer households would welcome more support to increase their productivity and improve their livelihoods more than small cash payments of this kind.

\subsection{Food price stabilisation measures}

From January 2013, the Ordinance on Prices has been replaced by the Law on Price 2012. Since the issuance of the law, the scope and circumstances for application of price registration and declaration has been narrowed significantly. Respecting the market mechanism and the right of business to determine prices, the state may exercise price regulation to stabilise prices or to protect the legitimate interest of business entities, and consumers or the national interest.

While the price stabilisation scheme has been governed by the government for years, resources have been inadequate for maintaining prices (e.g. financial support for food retailers to stabilise food prices). In some periods, rigid price stabilisation had been based on inexact predictions of market trends, which distorted the supply-demand balance, and caused difficulties to the import and export of agricultural products like sugar and rice. It has also been costly for local budgets because it involves tax concessions and interest rate subsidies and tends to have a low impact on price stabilisation, creating a two-price system. It is also relatively ineffective in terms of reaching the poor because it mainly affects prices in supermarkets which account for a small share of total domestic trade (less than 15 per cent), and their customers are mainly the middle classes in big cities.

\subsection{Policies on food quality and food safety standards}

Food safety issues have become more prominent in recent years. The government, ministries and local government have enacted different policies to improve food safety from production to consumption, including policies to support the development of safe food markets (ensuring food safety from initial stages of production, to the slaughter, processing, wholesale and retail markets). In 2008, the prime minister signed a decision approving policies to support the development of production, processing and consumption of VietGAP ${ }^{10}$ vegetables, fruits and tea. According to this decision, by 2015 all vegetables, fruit and tea production in the focus region for processing and export will meet safety requirements and will receive VietGAP certification. The government supports the cost of topographic surveys, identifies eligible production and supports construction and infrastructure improvements. Local governments support investment, storage, trade promotion and technology transfer.

From 2012, Decision No. 01/2012/QD-TTg has supported the adoption of VietGAP in agriculture, forestry and fisheries (replacing the 2008 Decision No. 107/2008/QD-TTg). This contributes to increased productivity and output, the improvement of farming techniques and aims to increase agricultural value added by over 30 per cent. The government support all costs which are associated with baseline surveys, topographical surveys, soil analysis, water sampling and air sampling to determine the production area for applying VietGAP while provincial authorities act as the main actor in this activity. From 2008 to 2013, funds for research and development have increased, and the MARD certified 162 technological processes and applications of crop cultivation and 266 Vietnamese standards for producing agricultural, aquacultural and forest products (Thang and Dinh 2014).

These policies play an important role in supporting farmers to apply food safety production standards. However, farmers cannot sustain good agricultural practices if they cannot earn a higher and more stable selling price from the market for these improved products. A key challenge here is that while most consumers want to buy safe foods, they often cannot tell them apart from food products grown without high standards. Public awareness about the GAP certificate granted to farm products that meet standards in production and postproduction processes has been low. People tend to be confused or to have no information about it.

In order to consolidate food safety management in the wholesale sector, MARD issued a circular on conditions of food safety in wholesale markets and 
agricultural auction centres ${ }^{11}$ and implemented another on monitoring (statistics, inspection and assessment) of food safety management. Agricultural producers and traders are classified into three levels of food safety, of which A is the best and C is the worst. The central and local governments also give training and financial support, in order to help farmers and traders to join or implement pilot models providing safe foods.

In order to assure food safety of imported agricultural products, MARD also issued circulars in 2010 and 2011 to support the market development of safe foods to control imported foods (with origin checks and sample tests). In the case of food safety violations, all products are to be destroyed, and names of offending importers will be published and announced to the relevant agencies of exporting countries.

In 2015, with the aim of socialising food safety management and in line with the government's administrative reform efforts, the Ministry of Health officially launched two public online services on food safety and hygiene. The first service receives documents from businesses asking for food safety approval, and the second grants certificates to certified restaurants. The online service facilitated businesses to carry out public services, while saving money, time and effort as well as avoiding corruption. According to the Food Administration of Vietnam, a part of the Ministry of Health, after four months' implementation of an online public service to grant certificates endorsing food safety, the administration has granted nearly 600 certificates via the internet.

While the government has instituted many new policies and programmes to improve the safety and quality of food supply, a number of gaps limit the benefits for poorer households. First, the food safety regulations are complex: there are around 400 documents issued by the central government and ministries and about 1,000 documents issued by local governments on food safety, many of which overlap and lack a clear focus. The overlap in responsibilities between the Ministry of Health, Ministry of Industry and Trade, Ministry of Agriculture and Rural Development has allowed many violations of food hygiene and safety regulations to slip through. This creates unfair competition in food markets and reduces incentives for food safety market development. It is very necessary to find out the important link between stakeholders in the food supply chain to assure the food safety in the whole supply chain. The scope and level adjustment of policies fail to meet the requirements of actual production-circulation, especially producers of small facilities whose businesses are not registered. Only a few actions have been taken to improve quality management and the safe food supply chain, which were assigned to separate quality and food safety management bodies, charged with enforcing good practices to minimise risk and raise food safety standards, and addressing incidents with sanctions. As the qualitative research shows, weaknesses in the food safety system primarily affect the small food producers and retailers, and the poorer consumers.

\section{Conclusion}

In the past few years, rising awareness about unsafe food has meant that people worry more about quality rather than quantity when it comes to food consumption, although they lack proper information about food production, processing and retail standards. Unsafe agricultural production remains a big issue in Vietnam because of unawareness of domestic producers, traders and consumers. After a long time of focusing on increasing food security in terms of quantities, time and effort are now needed to change the practice and awareness of stakeholders to move towards quality-oriented production and consumption.

The Vietnamese government has made great achievements in poverty reduction and food security. After the food crisis in 2008, the general price level of food has been more stable. Agricultural land area has reduced but with higher productivity, and the food supply remains assured. More and more actions to improve food quality and safety have been taken in recent times, including the application of the new food safety certification and controls system, but these chiefly focus on export foods because importers set higher standards of product quality than domestic consumers.

Facts and analysis from the case of Vietnam may provide some lessons for other countries in implementing food safety policy to support poor consumers to deal with food safety issues. More research and policy focus on three aspects is necessary:

1 Sustainable improvement of the food quality: creating reasonable incentives for food producers should be a key policy target. The policy should focus on investment in research and development (R\&D) and trade promotion in order to help producers to increase income and awareness on food safety, rather than giving them a small cash incentive to maintain production. 
2 Normalisation of food safety inspection protocols and the production of safe foods: unsafe agricultural production is still a big concern in Vietnam, especially in livestock and crop production. Vietnam needs appropriate policies to guarantee safe production and enhance collaboration between the state and the private sector in food safety monitoring. There is also a need to raise awareness and disseminate information on unsafe foods to the whole community.

3 The government should also improve inspections of safe products in order to build up consumers' trust in government-issued certificates. Companies providing safe agricultural products have to prove to the customers that they are qualified in their jobs. For example, all product information and origins should be visible on the product labels.

\section{Notes}

1 Resolution 30a. See www.chinhphu. vn/portal/page/portal/chinhphu/ hethongvanban?mode $=$ detail\&document_ id $=83020$.

2 IPSARD has a good database on daily prices which are collected every day from our local network in different provinces of Vietnam. Thanks to it being updated and being of reliable quality, this database is used not only for our research but is also available as a reference for other users. See http://ipsard.gov.vn/news/default.aspx.

3 VietGAP (Vietnamese Good Agricultural Practices) is a certificate granted to farm products that meet set standards in production and postproduction processes. VietGAP is applied to five agricultural products, including coffee beans, tea leaves, rice, fruit and vegetables.

414 November 2014, Hanoi City.

5 Nghi Văn Commune, Nghe An Province, 20 November 2014.

6 Luong an Tra Commune, Tri Ton District, An Giang Province, 5 November 2014.

\section{References}

FAO (2015) Statistics of FAO on Global Food Index, www.fao.org/worldfoodsituation/ foodpricesindex/en (accessed 2 September 2015)

GSO (2014) Socio-economic Annual Reports, Hanoi: Statistical Publishing House, https://gso.gov. vn/default.aspx?tabid=621\&ItemID $=14188$ (accessed 2 September 2015)

GSO (2013) Socio-economic Annual Reports, Hanoi: Statistical Publishing House, https://gso.gov. vn/default.aspx?tabid=621\&ItemID = 13843 (accessed 2 September 2015)
It requires the official agencies of health, agriculture and rural development as well as media organisations to provide information about the effect on health of food additives. Food additives and chemicals that are not permitted or whose use is unspecified must be banned.

Measures to improve the skills of inspectors and increase their accountability are also needed. Normalisation of food safety inspection protocols should be considered with the participation of social or economic associations. Inspections should be carried out across the whole food supply chain so that not only farm products but also food additives and food preservatives must also be tested. Cases of violation of regulations must be strictly handled and published widely in the mass media.

7 Nghi Văn Commune, Nghe An Province, 22 November 2014.

8 Resolution No. 63/NQ-CP. See http://vanban.chinhphu.vn/portal/page/portal/ chinhphu/hethongvanban?class_id=509\&_ page $=1 \&$ mode $=$ detail $\&$ document_id $=175693$.

9 Decree No. 42/2012/ND-CP in 2012, later replaced by Decree No. 35/2015/ND-CP in 2015. See www.chinhphu.vn/portal/page/portal/chinhphu/ hethongvanban?mode=detail \&document_ id $=158856$.

10 Decision No. 107/QD-TTg. See http://thuvienphapluat.vn/archive/Quyet-dinh107-2008-QD-TTg-chinh-sach-ho-tro-phat-triensan-xuat-che-bien-tieu-thu-rau-qua-che-an-toanden-nam-2015-vb69083.aspx.

11 According to Decree No. 38/2012/NĐ-CP on 25 April 2012, MARD is responsible for managing food safety in wholesale markets through agricultural product auction centres. See www.chinhphu.vn/portal/page/portal/chinhphu/ hethongvanban?mode $=$ detail\&document_ id $=158155$.

IDS (2014) Vietnam Report, 2014: Life in a Time of Food Price Volatility, Brighton: IDS, www.ids.ac.uk/ project/life-in-a-time-of-food-price-volatility (accessed 2 September 2015)

Thang, T.C. and Dinh, Bao Linh (2014) 'The Frame of Agricultural Policy and Recent Major Agricultural Policies in Vietnam', submitted as a country paper for the FFTG-COA International Workshop on Collection of Relevant Agricultural Policy Information and its Practical Use, Taipei, 23-7 June 2014 